\title{
Blocking by spironolactone (SC 9420) of the action of aldosterone upon the intestinal transport of potassium, sodium, and water
}

\author{
R. G. ELMSLiE 1 , ADELE T. MULHOLLAND ${ }^{2}$, AND R. SHIELDS ${ }^{3}$ \\ From the University Departments of Surgery, The Western Infirmary, Glasgow, and The Royal Infirmary, \\ Cardiff
}

EDITORIAL COMMENT This study continues the work described in the previous paper and brings out another common factor concerning electrolyte transport.

The action of the adrenal mineralocorticoids upon the intestinal mucosa closely resembles their effect upon the renal tubular epithelium (Shields, 1964). Thus, in both organs, the transfer of potassium into the lumen is stimulated by the intravenous administration of aldosterone (Barger, Berlin, and Tulenko, 1958; Shields, Mulholland, and Elmslie, 1966). Because the renal action of the mineralocorticoids can be blocked by the spironolactones (Bartter, 1960) the effect of these agents upon the intestinal action of aldosterone was investigated.

\section{METHOD}

The movement of potassium, sodium, and water into and out of the lumen of isolated segments of ileum (two dogs) and of colon (three dogs) was measured using the radioactive isotopes of sodium and potassium, and the stable isotope of water, deuterium oxide. Details of the preparation and of the experimental technique are given in the previous paper (Shields et al., 1966).

TYPES OF EXPERIMENT In each dog, six types of experiment were performed:-

1 Spironolactone alone One hundred $\mathrm{mg}$. spironolactone SC 9420 (Aldactone, Searle) was given by mouth at 6.00 a.m. At 9.00 a.m. an intravenous infusion of $5 \%$ $(\mathrm{w} / \mathrm{v})$ dextrose was set up and continued at a rate of $40 \mathrm{ml}$. per minute. Absorption tests, each lasting 10 minutes, were performed at $1,2,2 \frac{3}{4}, 3 \frac{1}{2}, 4$, and 5 hours after the beginning of the dextrose infusion. One such experiment was performed in each dog.

2 Spironolactone + aldosterone (high dose) The experimental technique was identical to (1), except that at 9.00 a.m., $250 \mu \mathrm{g}$. aldosterone (Aldocorten, Ciba) was injected intravenously and a further $250 \mu \mathrm{g}$. was added to the dextrose solution and delivered to the dog at a rate of $1 \mu \mathrm{g}$. per minute. One experiment of this type was performed on each dog.

3 Spironolactone + aldosterone (low dose) The experi-

${ }^{1}$ Present address: Department of Surgery, University of New South Wales, Sydney, Australia

2Present address: The Royal Infirmary, Stirling, Scotland

${ }^{3}$ Present address: The Surgical Unit, Royal Infirmary, Cardiff ment was similar to (1), except that aldosterone was added to the dextrose solution and infused intravenously at a rate of $8 \mu \mathrm{g}$. per hour. Two experiments of this type were performed on each dog.

4 Aldosterone (high dose) alone The technique was identical to (2) except that spironolactone was not given. Two such experiments were performed on each dog.

5 Aldosterone (low dose) alone The experimental procedure was identical to (3) except that no spironolactone was administered. One experiment of this type was performed upon each dog.

6 Control experiments Neither aldosterone nor spironolactone was administered, but, in all other respects, the experimental procedure was similar to that described in (1). Two control experiments were performed upon each dog.

The type of experiment performed was randomly selected on each occasion.

TERMINOLOGY 'Insorption' is applied to the movement of material into the body out of the intestinal lumen; 'exsorption' is used to describe movement in the opposite direction. When the rate of insorption exceeds that of exsorption, 'absorption' occurs; when the rate of exsorption is greater than that of insorption, the term 'secretion' is used.

Calculations The rates of movement of potassium, sodium, and water were calculated according to the method detailed in the previous paper.

\section{RESULTS}

The rates of transport of sodium and water across the mucosa of the ileum and the colon were not affected by aldosterone, by spironolactone, or by a combination of these drugs. Because there was no difference between the ileum and the colon in the effect of aldosterone, spironolactone, or both, upon potassium transport, the data obtained from both parts of intestine have been pooled for statistical analysis.

In each dog two control experiments and one 
spironolactone experiment were performed. Because of the variability in the rates of potassium transport between dogs, the effect of spironolactone alone upon each dog has been assessed by subtracting the transport rates under control conditions from those after spironolactone; from a series of such differences, the mean with its standard error has been calculated along with the probability that it differs from zero. These differences are shown in Table I. It is evident that the intestinal transport of potassium is not influenced by spironolactone in the dosage given.

\section{TABLE I}

MEAN RATES ( $\mu$ Eq./10 MIN.) OF POTASSIUM TRANSPORT UNDER CONTROL CONDITIONS AND MEAN DIFFERENCES AFTER SPIRONOLACTONE ${ }^{1}$

\begin{tabular}{llll} 
& Insorption & Exsorption & Net \\
\hline Control experiments & 15 & 33 & $-18^{2}$ \\
$\begin{array}{llll}\text { Difference when } \\
\text { spironolactone was given }\end{array}$ & $-1.3 \pm 1.7$ & $-5.0 \pm 6.0$ & $-6.3 \pm 7.6$ \\
P & $>0.4$ & $>0.4$ & $>0.4$
\end{tabular}

${ }^{1} \pm$ S.E. of difference: $P$, probability that the difference is zero. 'The minus sign preceding the mean rate of net potassium movement indicates secretion.

${ }^{3}$ The minus sign preceding the mean differences indicate a decrease below mean rates in control experiments.

To determine whether spironolactone blocked the intestinal action of aldosterone and to assess the extent of the block, two main effects are considered, using the method of analysis described by Mills, Thomas, and Williamson (1962). First, if the results of the experiments in which aldosterone plus spironolactone were given differed in the appropriate direction from those in which aldosterone was given alone, then spironolactone was considered to exert some blocking action. Secondly, if the results of experiments in which aldosterone plus spironolactone were given differed from those in which spironolactone was given alone, then the block was incomplete.

When aldosterone (low dose) was infused, the rate at which potassium ions entered the intestinal lumen (exsorption) was increased. If spironolactone were given beforehand, this increase in potassium exsorption was not observed (Table II). The blocking action of spironolactone seemed complete because the rates of exsorption of potassium, during the administration of spironolactone plus aldosterone (low dose) did not differ significantly from those observed after spironolactone alone (Table II). It was also noted that the rate of potassium insorption decreased with the administration of spironolactone plus aldosterone; however, this blocking action was not complete.

The intestinal action of aldosterone in high dose was not blocked by spironolactone in the dosage given (Table II).
TABLE II

MEAN RATES ( $\mu$ Eq./10 MIN.) OF POTASSIUM TRANSPORT IN ILEUM AND COLON AFTER ALDOSTERONE OR SPIRONOLACTONE AND MEAN DIFFERENCE AFTER BOTH DRUGS ${ }^{1}$

\begin{tabular}{|c|c|c|c|}
\hline & $n$ & Exso & $\mathrm{Net}^{2}$ \\
\hline \multirow{2}{*}{$\begin{array}{l}\text { Aldosterone (low dose alone) } \\
\text { Difference when spironolac- } \\
\text { tone was also given } \\
\mathbf{P}\end{array}$} & 15 & 70 & \\
\hline & $\begin{array}{l}-5.5 \pm 1.6 \\
<0.001\end{array}$ & $\begin{array}{l}-24.6 \pm 3.7 \\
<0.001\end{array}$ & $\begin{array}{l}+19.1 \pm 4.0 \\
<0.01\end{array}$ \\
\hline \multirow{2}{*}{$\begin{array}{l}\text { Spironolactone alone } \\
\text { Difference when aldosterone } \\
\text { (low dose) was also given }{ }^{3} \\
\text { P }\end{array}$} & 13 & 31 & \\
\hline & $\begin{array}{l}-4.5 \\
<0.0\end{array}$ & $\begin{array}{l}+2.0 \pm 6.0 \\
>0.7\end{array}$ & $\begin{array}{l}-6.5 \pm 5.7 \\
>0.2\end{array}$ \\
\hline gh dose) alone & 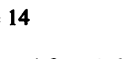 & 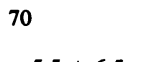 & -56 \\
\hline $\begin{array}{l}\text { spironolactone was given }{ }^{3} \\
\mathbf{P}\end{array}$ & $\begin{array}{l}-1.2 \pm 1.6 \\
>0.4\end{array}$ & $\begin{array}{l}-5.5 \pm 6.5 \\
>0.4\end{array}$ & $\begin{array}{l}-6 \cdot 7 \pm 7 \cdot 5 \\
>0.4\end{array}$ \\
\hline
\end{tabular}

$1 \pm$ S.E. of difference; $P$. probability that the difference is zero. ${ }^{2}$ The minus signs preceding the mean rates of net potassium transport indicate secretion.

${ }^{3} T h e$ plus and minus signs preceding the mean differences indicate increase above and decrease below mean rates when either aldosterone or spironolactone was given alone.

\section{DISCUSSION}

The spironolactones are assumed to act upon the kidney as competitive blockers preventing the access of the adrenal mineralocorticoids to their site of action on the renal tubules (Bartter, 1960). The sodium-retaining effect of aldosterone upon the kidney can be halved by spironolactone, this blocking action being incomplete (Mills et al., 1962). These authors found that in man the acute kaliuretic action of aldosterone was not sufficiently constant as to allow a clear assessment of the blocking action of spironolactone upon the renal handling of potassium. More recently Kagawa, Bouska, and Anderson (1964) found that the administration of spironolactone inhibited the effect of 11-de-oxycorticosterone on the renal handling of potassium. This blockade was complete.

The present study shows that the stimulating action of aldosterone, in low dose, upon the movement of potassium into the intestinal lumen, reported in the previous paper, could be completely blocked by spironolactone. The intestinal action of larger doses of aldosterone (whose effect on the gut was quantitatively identical to that of the smaller dose) could not be inhibited by spironolactone. The effect of administering larger doses of spironolactone has not been investigated. In this context it was of interest to note that the increased rates of potassium exsorption observed in sodium-depleted dogs could not be blocked by spironolactone (Clarke and Shields, 1963). Thus spironolactone seems incapable of inhibiting the action of aldosterone when excessive amount of the latter are present. 
The timing of the administration of spironolactone is of some importance. Edmonds and Wilson (1960) reported that the effect of a single oral dose of spironolactone was maximum between four and 10 hours after its administration and not much diminished after 14 hours. These observations guided us in the timing of the administration of spironolactone, the assumption being that spironolactone would produce its maximum effect at the same time as aldosterone.

The blocking effect of spironolactone upon the intestinal action of aldosterone provides further evidence of the close qualitative similarity between the intestinal and renal handling of electrolytes (Shields, 1964; Shields et al., 1966).

\section{SUMMARY}

The increase in the rate of movement of potassium ions into the lumen of isolated segments of ileum and colon of dogs, during the intravenous infusion of aldosterone, was not observed when spironolactone (SC 9420) was given beforehand. The action of larger doses of aldosterone could not be blocked. The block, when present, was complete.
We are indebted to Dr. H. J. E. Cox of G. D. Searle \& Co., Ltd. for the generous gift of spironolactone, to Dr. A. K. Pitman of Ciba Laboratories for aldosterone, and to Mr. R. W. Larkin of the London Rubber Company for the miniature balloons used in the construction of the absorption tubes.

Part of this work was supported by a grant from the Medical Research Council.

\section{REFERENCES}

Barger, A. C., Berlin, R. D., and Tulenko, J. F. (1958). Infusion of aldosterone, 9-a-fluorohydrocortisone and antidiuretic hormone into the renal artery of normal and adrenalectomized unanesthetized dogs: effect on electrolyte and water excretion. Endocrinology, 62, 804-815.

Bartter, F. C. (1960). The Clinical Use of Aldosterone Antagonists. Thomas, Springfield, Ill.

Clarke, A. M. and Shields, R. (1963). The role of the intestine in fluid and electrolyte conservation during sodium depletion. (Abstract). Brit. J. Surg., 50, 768.

Edmonds, C. J. and Wilson, G. M. (1960). The action of hydroflumethazide in relation to adrenal steroids and potassium ions. Lancet, 1, 505-509.

Kagawa, C. M., Bouska, D. J., and Anderson, M. L. (1964). Further notes on the interaction of spironolactone and deoxycorticosterone acetate in dogs. Acta endocr. (Kbh.), 45, 79-83.

Mills, J. N., Thomas, S., and Williamson, K. S. (1962). The blocking by spironolactones of the actions of aldosterone and cortisol upon the human kidney. J. Endocr., 23, 357-363.

Shields, R. (1964). Surgical aspects of the absorption of water and electrolytes by the intestine. Monogr. surg. Sci., 1, 119-172.

-, Mulholland, A. T., and Elmslie, R. G. (1966). The action of aldosterone upon the intestinal transport of potassium, sodium and water. In the press. 